\title{
ESTRATÉGIAS DE NEGÓCIO E UNIVERSIDADES CORPORATIVAS: UM ESTUDO NO SETOR FARMACÊUTICO
}

\section{BUSINESS STRATEGIES AND CORPORATE UNIVERSITIES: A STUDY IN THE PHARMACEUTICAL SECTOR}

\author{
João Victor Bonini Viana ${ }^{1}$; Roberto Marx ${ }^{2}$ \\ ${ }^{1}$ Escola Politécnica da Universidade de São Paulo - USP - São Paulo - Brasil \\ jvbv@terra.com.br \\ ${ }^{2}$ Escola Politécnica da Universidade de São Paulo - USP - São Paulo - Brasil \\ robemarx@usp.br
}

\begin{abstract}
Resumo
Este artigo procurou discutir as relações entre estratégias de negócios e as competências individuais eu os programas de Universidade Corporativa se propõem a desenvolver junto aos funcionários de organizações. As estratégias de negócios foram estudadas em duas perspectivas: segundo as estratégias baseadas na análise dos produtos, dos consumidores e competidores e nas estratégias com abordagem condicionada à combinação do desenvolvimento de competências e de recursos. No que tange à Universidade Corporativa foram citadas suas iniciativas de aprendizado $e$ as competências individuais criadas. Por se tratar de um estudo de natureza exploratória, utilizou-se o método qualitativo, com pesquisa baseada em entrevistas realizadas em uma empresa privada de grande porte, do setor farmacêutico. Posteriormente, empregou-se a análise de conteúdo por categorização a priori e a posteriori como técnica de tratamento de dados. Os resultados evidenciaram que a organização considera tanto fatores externos quanto internos na formulação de suas estratégias e que a Universidade Corporativa contribui por meio de seus programas com o desenvolvimento de competências que ajudam os colaboradores a fazerem as estratégias acontecerem de fato.
\end{abstract}

Palavras-chave: estratégias de negócio; universidade corporativa; setor farmacêutico.

\section{Introdução}

Vive-se um período de intensas e velozes transformações. Num contexto empresarial de turbulências, três ondas de mudanças podem ser destacadas: a primeira modificou o regime de mercado de vendedor para comprador, a segunda foi marcada pela globalização dos mercados e a terceira refere-se ao advento da economia baseada no conhecimento. Tais mudanças levam consigo novas formas de organização empresarial (FLEURY; FLEURY, 2002).

Nesse contexto extremamente competitivo e integrado emerge a economia do conhecimento, conhecimento este que se torna o principal fator de produção. A cada dia, empresas incorporam este 
novo paradigma às suas decisões, procurando focar nas atividades agregadoras de valor. As estratégias organizacionais passam a adotar, progressivamente, o foco na concepção dos produtos e nos sistemas de produção, sendo as atividades rotineiras entregue a terceiros (FLEURY; FLEURY, 2002).

Os fatores que determinam a competitividade de uma empresa podem ser analisados em duas perspectivas: "de fora para dentro" e "de dentro para fora".

A primeira, "de fora para dentro", enfatiza "[...] a análise de mercados e da competição e o entendimento da posição relativa de cada empresa em sua indústria ou segmento produtivo como elementos primordiais no processo de formulação da estratégia" (FLEURY; FLEURY, p. 54, 2002). Nessa perspectiva, as estratégias das empresas são baseadas na análise dos concorrentes, dos consumidores e fornecedores, na identificação de tendências e oportunidades (PORTER, 1990).

Já a abordagem "de dentro para fora" fundamenta-se sobre a "visão da empresa baseada em recursos" (VBR). Esta considera que todas as empresas possuem um portfólio de recursos, de onde podem criar suas vantagens competitivas. Assim, as definições das estratégias devem partir da compreensão das possibilidades passíveis de serem operacionalizadas a partir dos recursos, tangíveis e intangíveis que a empresa possui. O sucesso da organização, segundo esta perspectiva está condicionada à combinação do desenvolvimento de competências que se dá através da capacitação profissional de seus colaboradores e da otimização dos demais recursos (FLEURY; FLEURY, 2002).

Nessa segunda perspectiva, o desenvolvimento e o treinamento assumem maior importância na formulação das estratégias empresariais passando a ser tratados dentro das chamadas universidades corporativas. Éboli (2002, p. 185) afirma que, “de acordo com estimativas recentes, milhares de empresas norte-americanas criaram universidades-empresas, faculdades e institutos de ensino para satisfazer as carências de conhecimentos dos empregados, buscando melhores formações profissionais para melhores vantagens competitivas".

A Universidade Corporativa nasce como resposta estratégica para o alinhamento e desenvolvimento dos funcionários nas empresas ao aplicarem o conceito de competências na gestão de um sistema de desenvolvimento de pessoas. Na concepção da universidade corporativa, o conceito de competência é incorporado e assimilado como valor da empresa, que tende a contratar, remunerar e avaliar levando-o sempre em consideração (MEISTER, 1999).

Neste artigo procurar-se-á entender a universidade corporativa e sua interface de seus programas com as estratégias de negócios.

A importância desse estudo se dá pelo fato de que o conceito de Universidade Corporativa está ainda muito pouco difundido no Brasil. No contexto nacional, pesquisa realizada por Marcondes e Paiva (2001) mostra que as empresas não estão plenamente compromissadas em 
desenvolver talentos humanos para gestão dos negócios, pois ainda não está clara a conexão do treinamento e desenvolvimento com as estratégias de negócios das empresas.

Para que a concepção de Universidade Corporativa não esteja associada somente ao sentido de divulgação mercadológica, gerando apenas ganhos de imagem, ela deve pautar suas ações de forma real, na construção crítica de competências para a organização (DENGO, 2002).

Este artigo tem como objetivo geral discutir as relações entre estratégias de negócio e as competências individuais que os programas de Universidade Corporativa se propõem a desenvolver junto aos funcionários de organização. Como objetivos específicos procurar-se-á: conhecer as estratégias de negócio da empresa e as competências individuais que a Universidade Corporativa pretende desenvolver com seus programas de desenvolvimento.

Por se tratar de um estudo de natureza exploratória, utilizou-se do método qualitativo, com pesquisa baseada em entrevistas, realizadas em uma empresa privada de grande porte, de capital estrangeiro, do setor farmacêutico, denominada neste trabalho como "Farmacêutica S.A."

Como contribuições este estudo busca dar respostas a algumas questões e estimular o surgimento de outras, referentes aos temas. Espera-se gerar conhecimento acadêmico e ajudar os gestores que lidam com questões referentes a estratégias e educação continuada, a refletirem sobre ambas no cotidiano empresarial.

\section{Referencial teórico}

\subsection{Estratégias de Negócio}

\subsubsection{Conceituação e Evolução}

A preocupação com a estratégia tem ocupado um espaço cada vez maior nas discussões empresariais, nos debates acadêmicos e na literatura de administração. Esse fato está relacionado com o acirramento da competição no nível local, regional e global, bem como com a revolução tecnológica e a do conhecimento (ALBUQUERQUE, 2002).

Existem três escolas - design, planejamento e posicionamento - que são consideradas de natureza prescritiva, mais preocupadas em quais as estratégias devem ser formuladas do que em como elas são formuladas. Já as escolas do segundo grupo - empreendedora, cognitiva, de aprendizado, do poder, cultural e ambiental - estão mais voltadas para a análise de como as estratégias são de fato formuladas. Finalmente, a escola de configuração combina contribuições de várias outras, descrevendo a estratégia como um processo de mudança (ALBUQUERQUE, 2002).

Assim cada uma dessas escolas expõe conceitos diferentes, não necessariamente conflitantes e complementares à estratégia. Desmistificam a complexidade de um conceito tão importante e abrangente, apresentando o benefício dessas diferentes contribuições, que possuem certos pontos 
em comum (ALBUQUERQUE, 2002), quais sejam:

- $\quad$ a estratégia dá direção, fornece o direcionamento da empresa e provê consistência;

- $\quad$ a estratégia resulta de um processo de decisão;

- $\quad$ as decisões são principalmente de natureza qualitativa, interferem no todo da organização e buscam eficácia a longo prazo;

- $\quad$ a estratégia abrange a organização e sua relação com o ambiente;

- $\quad$ a estratégia envolve questões de conteúdo e do processo, em diferentes níveis.

Este trabalho adotará como conceito de estratégia o conjunto de ações que uma companhia toma para atingir um ou mais de seus objetivos, alcançando um nível superior de eficácia (vantagem competitiva).

\subsubsection{Perspectivas para a formulação de estratégias "de fora para dentro"}

As estratégias das empresas que consideram em sua formulação aspectos externos à organização, relativos ao setor, são baseadas em Porter (1986) na análise dos concorrentes, dos consumidores e fornecedores, na identificação de tendências e oportunidades.

\subsubsection{Modelo competitivo das cinco forças}

Os posicionamentos propostos por Porter (1980) são decorrentes das cinco forças competitivas: entrada de novos competidores, a ameaça de produtos substitutos, o poder de negociação dos compradores, o poder de negociação dos fornecedores e a rivalidade entre os competidores existentes.

\section{Ameaça de Novos Entrantes}

A entrada de novas empresas em um segmento na busca de maior fatia de mercado está diretamente relacionada aos níveis existentes de barreiras de entradas. Estas barreiras influenciam na tomada de decisão, de entrar ou não, ou de que forma entrar. Nessa competição as empresas terão pontos fortes e pontos fracos ao se posicionarem no mercado (PORTER, 1999).

\section{Poder de barganha de Fornecedores}

Os fornecedores podem pressionar pelo aumento dos preços e reduzir o potencial de lucratividade da empresa. É neste momento que a empresa adquirente poderá perder competitividade no mercado e seus lucros se tornam decrescentes em virtude da mesma não conseguir repassar os aumentos de custos (PORTER, 1999).

\section{Poder de barganha dos Compradores}

A competição provocada pelos compradores é aquela em que existe uma pressão dos preços para baixo fazendo com que obtenham grandes descontos, e consigam grande atenção e melhorias 
nos serviços (PORTER, 1999).

\section{Ameaça de produtos substitutos}

$\mathrm{Na}$ competição ampla, as empresas estão concorrendo com competidores que fabricam produtos substitutos aos seus. Em virtude desta concorrência o setor sofre restrições de crescimento e reduções em seu potencial de lucratividade. Ou seja, os produtos substitutos provocam a redução nos retornos potenciais de uma empresa, e ainda nivelam os preços fixando um teto (PORTER, 1999).

\section{Rivalidade entre concorrentes}

Os concorrentes existentes disputam uma posição mais rentável no setor em que atuam com o uso de diversas estratégias. Os movimentos de um competidor têm efeitos notáveis em outros competidores e estes podem assim iniciar manobras para conter as ações dos iniciantes. Este movimento poderá levar a empresa iniciante tanto ao aprimoramento da empresa quanto de seus concorrentes (PORTER, 1999).

\subsubsection{Estratégias competitivas genéricas}

Para enfrentar as cinco forças competitivas, Porter (1999) propõe três abordagens estratégicas genéricas potencialmente bem sucedidas para superar as outras empresas em uma indústria.

\section{Liderança no custo total}

$\mathrm{Na}$ liderança de custo, o foco da empresa está voltado para produzir com baixo custo dentro de seu ramo, ou seja, o menor custo em relação à concorrência. Esta vantagem é obtida através da adoção de um conjunto de políticas funcionais voltadas para este objetivo, bem como o desenvolvimento de atividades econômicas e tecnológicas a um custo menor que a de seu concorrente (PORTER, 1999).

Desta forma, o foco da liderança de custo fundamenta-se na idéia de que a empresa mais competitiva é aquela que possui menores custos, os quais podem resultar de um exame de cada atividade da empresa na busca de oportunidades para reduzir o custo, e a busca consistente de todas elas.

\section{Diferenciação}

A diferenciação consiste na criação de um produto ou serviço que seja único no âmbito de toda a indústria. Para isso, a empresa deve desenvolver atividades com alta qualidade, de tal forma a gerar oferta de benefícios diferenciados que torne o seu produto mais atraente aos olhos do consumidor do que o de seus concorrentes (PORTER, 1999).

\section{Enfoque}

A estratégia genérica do enfoque tem como objetivo a concentração em um determinado 
grupo comprador, um segmento da linha de produtos ou um mercado geográfico. Esta estratégia define a capacidade de atendimento pela empresa de um determinado alvo, e se as políticas funcionais estão voltadas para tal. O objetivo da estratégia de enfoque é atender melhor seu alvo estratégico se comparado aos seus concorrentes (PORTER, 1999). Entretanto, a adoção da estratégia de enfoque implica algumas limitações na parcela total do mercado que pode ser atingida, bem como um necessário trade-off entre rentabilidade e volume de vendas.

\subsubsection{Perspectivas para a formulação de estratégias "de dentro para fora"}

O conceito de Porter (1996) de posicionamento estratégico parte da análise da indústria e do entendimento da posição competitiva que uma organização deve adotar na formulação de sua estratégia. O foco é a análise do mercado e dos competidores, sendo a vantagem competitiva derivada da exploração das oportunidades e tendências encontradas no ambiente externo (FLEURY; FLEURY, 2002).

No entanto, é também através da análise interna, que observa os recursos únicos, capacidades e competências essenciais (HITT; IRELAND; HOSKISSON, 1990) que as organizações podem alcançar vantagem competitiva.

\subsubsection{De recursos a competências essenciais}

A abordagem "de dentro para fora" dos recursos da firma, enfatiza a maior importância de se centrar a formulação estratégica em um grupo específico de recursos - aqueles que garantem lucratividade de longo prazo. Essa abordagem distingue entre recursos e competências. "Um recurso é algo que a organização possui ou tem acesso, mesmo que esse acesso seja temporário... uma competência é uma habilidade para fazer alguma coisa. [...] uma competência é construída a partir de um conjunto de 'blocos' denominados recursos." (MILLS et al. apud FLEURY; FLEURY 2002, p. 55)

Fleury e Fleury (2002, p.34) definem as competências individuais como um "saber agir responsável e reconhecido, que implica mobilizar, integrar, transferir conhecimentos, recursos e habilidades que agreguem valor econômico à organização e valor social ao indivíduo.”

Já as competências organizacionais são competências coletivas associadas às atividadesmeios e às atividades-fins (FLEURY; FLEURY, 2002). O conceito de competência organizacional tem suas raízes na abordagem da organização como um portfólio de recursos. Essa abordagem considera que toda empresa tem um portfolio: físicos (infra-estrutura), financeiros, intangíveis (marca, imagem, etc.), organizacionais (sistemas administrativos, cultura organizacional) e recursos humanos (HAMEL; PRAHALAD, 1995). 


\subsubsection{Estratégias a partir das competências}

A formulação de estratégias a partir das competências é importante para as empresas que se inserem em um contexto de alta competitividade, como o que caracteriza os mercados atuais (FLEURY; FLEURY, 2002).

\section{Estratégia de Excelência Operacional}

Caracterizada por empresas que competem com base no custo e que procuram oferecer aos seus clientes um produto médio com o melhor preço e bom atendimento (FLEURY; FLEURY, 2002).

Treacy e Wiersema (1995) enfatizam que as empresas operacionalmente excelentes integram uma combinação de qualidade, preço e facilidade de compra.

A função crítica para o sucesso da companhia que utiliza este tipo de estratégia de negócio é a função "Operações”, incluindo todo o ciclo Logístico: Suprimento, Produção e Distribuição. É nessa função que reside a competência essencial, aquela que deve ser priorizada para que a empresa seja competitiva (FLEURY; FLEURY, 2002).

\section{Estratégia de Produtos Inovadores}

As empresas que competem com uma estratégia de produtos inovadores estão continuamente investindo para criar conceitos de produto radicalmente novos, para clientes e segmentos de mercado definidos. A função crítica é Pesquisa \& Desenvolvimento e Engenharia (P\&D\&E). Procuram oferecer aos seus clientes produtos de ponta, inovando sempre (FLEURY; FLEURY, 2002).

O sucesso econômico das empresas que competem sob essa estratégia é garantido pela alta lucratividade que alcançam no período em que usufruem de posição de monopólio de mercado. Assim, o que é crítico para esse tipo de companhia é a rápida concepção de novos produtos e de seus respectivos processos de produção, para passar da escala laboratorial para a escala industrial (FLEURY; FLEURY, 2002).

\section{Estratégia de Orientação para Clientes}

As empresas que adotam a estratégia de orientação para o cliente são voltadas para as necessidades de clientes específicos, individualizados, procurando se especializar no desenvolvimento de produtos, sistemas e soluções que atendam às suas demandas atuais e futuras (FLEURY e FLEURY, 2002).

Fleury e Fleury (2002, p. 65) observam que esta estratégia é adequada para "empresas que se especializam em satisfazer, e até antecipar, os desejos do cliente em virtude de sua proximidade com eles". Treacy e Wiersema (1995) concordam que as empresas próximas aos clientes não entregam aquilo que o mercado quer, mas aquilo que um cliente específico deseja, já que priorizam 
o desenvolvimento de profundo conhecimento sobre cada cliente e seu negócio.

Considerações sobre as estratégias formuladas sob a perspectiva "de dentro para fora"

O Quadro 1 resume as estratégias definidas a partir de uma perspectiva "de dentro para fora", com base nas competências essenciais.

Quadro 1 - Estratégias definidas a partir de uma perspectiva "de dentro para fora"

\begin{tabular}{|c|c|c|c|}
\hline \multirow{2}{*}{ Estratégia empresarial } & \multicolumn{3}{|c|}{ Competência na função } \\
\hline & Operações & Produto & Marketing \\
\hline Excelência Operacional & $\begin{array}{l}\text { Manufatura de classe } \\
\text { mundial }\end{array}$ & Inovações Incrementais & $\begin{array}{l}\text { Marketing de produtos para } \\
\text { mercados de massa }\end{array}$ \\
\hline Produtos Inovadores & $\begin{array}{c}\text { Scale up e fabricação } \\
\text { primária }\end{array}$ & $\begin{array}{l}\text { Inovações radicais } \\
\text { (breakthrough) }\end{array}$ & $\begin{array}{l}\text { Marketing técnico pra } \\
\text { mercados/clientes } \\
\text { receptivos a inovação }\end{array}$ \\
\hline Orientação para o cliente & Manufatura ágil, flexível & $\begin{array}{l}\text { Desenvolvimento de } \\
\text { soluções e sistemas } \\
\text { específicos }\end{array}$ & $\begin{array}{l}\text { Marketing voltado a } \\
\text { clientes específicos }\end{array}$ \\
\hline
\end{tabular}

Fonte: Baseado em Fleury (2002)

\subsection{Universidades corporativas}

\subsubsection{A universidade corporativa no ambiente empresarial}

A partir da década de 1980, observou-se um aumento considerável de um novo tipo de espaço de formação profissional. Segundo o estudo "Diretrizes Futuras da Universidade Corporativa", publicado pela consultoria Corporate University Xchange (CUX), existiam 400 universidades corporativas nos EUA, em 1988. Estima-se que em 2010 elas irão superar o número de universidades tradicionais nos Estados Unidos - cerca de 3 mil (GDIKIAN; SILVA, 2002).

De acordo com estimativas recentes, milhares de empresas norte-americanas criaram estas "universidades-empresa", "faculdades" e "institutos de ensino" para satisfazer as carências de conhecimento de seus empregados (MEISTER, 1999).

Fischer (2002) observa que: "o momento é de disseminação das Universidades Corporativas pelo país. Elas precisam se institucionalizar, ser reconhecidas e explicadas". O próprio autor afirma que embora em fase de consolidação, depuração e permanência, o especialista não a considera modismo, mas algo que veio para ficar.

A educação corporativa é, hoje, uma realidade no meio empresarial, muito em função do avanço da tecnologia que proporcionou uma economia com o aperfeiçoamento de ensino à distância, fundamentado na necessidade de atualizar os conhecimentos (CIRILO, 2004).

Gdikian e Silva (2002) vêem a Universidade Corporativa como uma nova ferramenta de gestão de pessoas e conhecimento, a qual está ligada diretamente ao desenvolvimento da organização e do mercado. Assim, entender como esta funciona e como é inserida em uma instituição, agrega um grande diferencial para os administradores e para as empresas relacionadas. 
Éboli (2002) observa ainda que algumas Universidades Corporativas focam no desenvolvimento de competências, outras no desenvolvimento do negócio, outras são orientadas aos clientes. Têm em comum, o foco em prover oportunidades de aprendizado para suportar os objetivos estratégicos de negócios e disseminar a cultura organizacional.

\subsubsection{Princípios da universidade corporativa}

Segundo Éboli (2002), os princípios são as bases filosóficas e os fundamentos que norteiam uma ação, ou seja, são elementos qualitativos predominantes na constituição de um sistema de educação corporativa bem sucedido. São os princípios que darão origem à elaboração de um plano estratégico consistente e de qualidade. Para que o conceito de Universidade Corporativa se torne realidade, é necessário fazer escolhas organizacionais integradas sob o ponto de vista da cultura, da estrutura da empresa, da tecnologia, dos processos e do modelo de gestão empresarial (em especial o modelo de gestão de pessoas por competências). Essas escolhas devem favorecer decisões pessoais que transformem esses princípios em ações, práticas, hábitos e exercícios corporativos, capazes de gerar um comportamento cotidiano nos colaboradores, coerente com a estratégia definida.

\subsubsection{Objetivos da universidade corporativa}

A Universidade Corporativa tem como foco o desenvolvimento e retenção do capital intelectual e o fomento à cultura de inovação na empresa. Seus objetivos são a formação de uma inteligência corporativa, baseada nos princípios de colaboração e compartilhamento de conhecimento; a elevação do nível de competências sociais e de convivência e a efetividade dos processos de comunicação e informação distribuída (GOULART; PESSOA, 2004).

As Universidades Corporativas, portanto, têm como objetivo desenvolver nos profissionais as competências essenciais para a viabilização das estratégias empresariais, enquanto as escolas tradicionais têm como objetivo desenvolver nos profissionais as competências essenciais para o mundo do trabalho (ÉBOLI, 2002).

\subsubsection{Importância do vínculo entre as estratégias de negócios e o gerenciamento estratégico de recursos humanos na perspectiva da educação corporativa}

Considerando-se o que já foi apresentado, pode-se dizer que o papel da Universidade Corporativa é fundamental nos dias de hoje. Suas atribuições vêm, progressivamente, sendo elaboradas por educadores, empresários e outros segmentos interessados em refletir sobre os desafios que se impõem à realidade empresarial brasileira, de modo a que possa levar as empresas a 
um grau de competitividade e modernidade compatível com as exigências do atual mundo dos negócios (GDIKIAN; SILVA, 2002).

\section{Necessidade de parceria com a gerência}

Conforme Éboli (2002), com o apoio da gerência, a Universidade Corporativa cumprirá o papel de principal veículo de integração e disseminação de uma cultura empresarial de competência e resultado. Apoiará todos os talentos internos e externos no processo de aquisição das competências humanas essenciais, que irão agregar valor ao negócio, gerando resultado para a empresa, seus clientes, acionistas e comunidade.

O programa estratégico estabelecido pela Universidade Corporativa deve ser objetivo e claro, visualizando a empresa como um todo; capaz de ser compreendido como um todo e por todos; capaz de ser compreendida em toda a instância decisória quanto aos princípios, propósitos e ações que expressa. A conscientização de gestores e facilitadores de aprendizagem é o principal passo para difundir na empresa uma cultura de capacitação, desenvolvimento e atualização (GOULART; PESSOA, 2004).

\section{Vínculo com as necessidades do negócio}

Visando identificar pessoas com potencial de crescimento, flexibilidade para enfrentar os incidentes críticos e as novas demandas das empresas, as organizações que passaram a adotar a concepção de Universidade Corporativa devem encarar todo o processo de desenvolvimento das pessoas de forma alinhada às estratégias de negócios e às competências essenciais da organização (FLEURY; FLEURY, 2002).

\subsubsection{Tipos de competências desenvolvidas pelas universidade corporativa}

“O conhecimento é a nova base para a formação de riqueza, quer seja no âmbito individual, empresarial ou nacional". A rápida obsolescência do conhecimento está associada a esse sentido de urgência (ÉBOLI, 1999, p. 128).

Éboli (1999) vê uma mudança fundamental no mercado da educação global, evidenciando-se a necessidade de formar pessoas com visão global e perspectiva internacional dos negócios. Essas tendências apontam fortemente para um novo cenário internacional dos negócios e importante aspecto na criação de uma vantagem competitiva sustentável.

Conforme Goulart e Pessoa (2004), o foco é na aprendizagem contínua e no desenvolvimento permanente dos empregados, de forma orientada e acompanhada. As soluções de aprendizagem devem ser centradas em aprendizagens significativas e garantir o estreito vínculo entre o conhecimento e a realidade de trabalho do empregado.

Para tanto, Éboli (2002) aponta que a Universidade Corporativa está para o conceito de competências assim como os tradicionais centros de T\&D estiveram para o conceito de cargo. 
As Universidades Corporativas atuam no sentido de ampliar a interação entre os novos elementos do aprendizado e os conhecimentos já existentes (ÉBOLI, 2002)

Fleury e Fleury (2002), por sua vez, consideram a formação de competências individuais mais diretamente ligadas ao processo de trabalho e às estratégias de negócio, propondo uma categorização em três grandes blocos, que envolvem a relação do indivíduo com toda a empresa, são eles:

\section{Competência de negócio}

São as competências relacionadas à compreensão do negócio, seus objetivos relacionados com mercado, clientes e competidores, assim como no ambiente político e social (FLEURY; FLEURY, 2002).

\section{Competências técnico-profissionais}

São competências específicas para certa operação, ocupação ou atividade tais como conhecimento do produto, finanças (FLEURY; FLEURY, 2002).

\section{Competências sociais}

São necessárias para promover o relacionamento interpessoal, tais como, comunicação, negociação, mobilização para mudança, sensibilidade cultural, trabalho em times (FLEURY; FLEURY, 2002).

Relacionando esses conjuntos de competências, desenvolvidas pelos indivíduos em seus respectivos espaços de atuação, com as estratégias de negócio, é possível desenvolver competências essenciais e ser competitivo no mercado (FLEURY; FLEURY, 2002).

\section{Metodologia de pesquisa}

\subsection{Problema de pesquisa}

O problema de pesquisa questiona como as variáveis, em estudo, estão ou podem estar relacionadas. Segundo Cervo (2002), o problema é uma questão que envolve intrinsecamente uma dificuldade teórica ou prática, para a qual se deve encontrar uma solução.

Desta forma, o presente estudo apresenta o seguinte problema de pesquisa:

Existe relação entre as estratégias de negócios e as competências desenvolvidas por meio da universidade corporativa nos funcionários de organizações?

\subsection{Variáveis}

Existem diversas formas de classificar as variáveis de um problema de pesquisa. Uma das mais usuais é dada pela relação existente entre elas, denominando-se dependentes e independentes. 
Dependente é aquela que é afetada pela variável independente, já a independente é a variável que causa ou condiciona uma alteração na variável dependente (RICHARDSON, 1999).

Neste contexto, o presente estudo, por buscar verificar a relação entre as variáveis Estratégias de Negócio e Competências Individuais, sem estabelecer um sentido, de causa e efeito, não utilizará esta classificação.

Neste artigo, definem-se Estratégias de Negócio como: um conjunto de ações que uma companhia toma para atingir um ou mais de seus objetivos, alcançando um nível superior de eficácia (vantagem competitiva), podendo ser estabelecidas segundo as cinco forças de Porter (1986), seguindo uma abordagem de "fora para dentro", e também ao considerar os recursos e as competências organizacionais elementos de uma abordagem "de dentro para fora" (FLEURY; FLEURY, 2002).

Fleury e Fleury (2002, p.34) definem as competências individuais como um "saber agir responsável e reconhecido, que implica mobilizar, integrar, transferir conhecimentos, recursos e habilidades que agreguem valor econômico à organização e valor social ao indivíduo". As competências individuais a serem desenvolvidas pelos programas da Universidade Corporativa foram classificadas em competências de negócio, técnico-profissionais e sociais.

\subsection{Objetivo}

Os objetivos definem a natureza do estudo, o tipo de problema a ser solucionado. Os objetivos podem ser divididos em Geral e Específicos (CERVO; BERVIAN, 2002).

\subsubsection{Objetivo geral}

O Objetivo Geral, segundo Marconi e Lakatos (1999), deve expressar claramente aquilo que o pesquisador pretende conseguir com sua investigação, delimitando e dirigindo os raciocínios a serem desenvolvidos. É construído a partir do problema de pesquisa, acrescido de um verbo de ação intelectual, na forma afirmativa.

O presente estudo tem como Objetivo Geral:

- Descobrir se existem relações entre estratégias de negócios e as competências individuais que os programas de Universidade Corporativa se propõem a desenvolver nos empregados de organizações.

\subsubsection{Objetivos específicos}

Por outro lado, os Objetivos Específicos, segundo Richardson (1999), correspondem a aspectos específicos dos fenômenos que se pretende estudar e que contribuem para alcançar o 
objetivo geral. Definem as etapas que devem ser cumpridas para seu alcance.

Como Objetivos Específicos tem-se:

- $\quad$ Conhecer as estratégias de negócio da empresa, segundo as perspectivas de "fora para dentro" e de "dentro para fora";

- Conhecer as competências individuais que a Universidade Corporativa pretende desenvolver com seus programas de desenvolvimento.

\subsection{Natureza da pesquisa}

As pesquisas podem ser classificadas em três grandes grupos: exploratórias, descritivas e explicativas (GIL, 1996).

Pesquisas exploratórias têm como objetivo proporcionar maior familiaridade com o problema, com vistas a torná-lo mais explícito ou a constituir hipóteses, segundo Gil (1996). “A pesquisa exploratória realiza descrições precisas da situação e quer descobrir as relações existentes entre os elementos componentes da mesma" (CERVO; BERVIAN, 2002, p. 69)

Segundo Richardson (1999), as pesquisas descritivas têm o propósito de fazer afirmações com o objetivo de descrever uma população ou analisar a distribuição de determinadas características. "As pesquisas descritivas têm como objetivo primordial a descrição das características de determinada população ou fenômeno ou, então, o estabelecimento de relações entre variáveis" (Gil, 1996, p. 42).

Já as pesquisas explicativas têm como preocupação central identificar os fatores que determinam ou contribuem para a ocorrência dos fenômenos. Esse é o tipo de pesquisa que mais aprofunda o conhecimento da realidade, porque explica a razão, o porquê das coisas (Gil 1996).

O presente estudo caracteriza-se como uma pesquisa exploratória, pois tem por objetivo descobrir a existência de relações entre as estratégias de negócios e as competências individuais que os programas de Universidade Corporativa se propõem a desenvolver nos empregados, a partir de uma única empresa, tentando levantar hipóteses para futuros estudos.

\subsection{Métodos de pesquisa}

Segundo Richardson (1999), “em sentido genérico, método em pesquisa significa a escolha de procedimentos sistemáticos para a descrição e explicação de fenômenos [...] podemos dizer que há dois grandes métodos: o quantitativo e o qualitativo". O método quantitativo caracteriza-se pelo emprego da quantificação nas fases de coleta de dados e tratamento; neste último por meio de técnicas estatísticas.

O presente estudo utilizou o método qualitativo, uma vez que envolve a obtenção de dados descritivos sobre processos interativos mediante o contato direto do pesquisador com a situação 
estudada, procurando compreender os fenômenos segundo a perspectiva dos participantes da situação em estudo.

\section{Pesquisa Qualitativa}

Segundo Godoy e Alves (2004), as entrevistas constituem um método de coleta de dados pelo qual se selecionam participantes que respondam questões tentando descobrir o que fazem, pensam ou sentem, podendo ser desenvolvidas individualmente ou em grupo.

Este estudo utilizou a Pesquisa Qualitativa baseado em entrevistas, pois foi o caminho possível encontrado para se atingir os objetivos de pesquisa já citados. Complementarmente, recorreu-se a dados secundários, provenientes da Intranet da organização pesquisada.

\subsection{Participantes da pesquisa}

Este artigo foi realizado em uma das maiores empresas do ramo farmacêutico, transnacional, denominada aqui por "Farmacêutica S/A" onde havia uma maior facilidade de acesso dos pesquisadores ao público-alvo: gerentes e responsáveis pela Universidade Corporativa.

O Quadro 2 apresenta o perfil dos respondentes das entrevistas efetuadas.

Quadro 2 - Características dos Participantes da Pesquisa

\begin{tabular}{|c|c|c|c|c|c|c|c|}
\hline Entrevistado & Sexo & Cargo & Área & Idade & $\begin{array}{l}\text { Tempo de } \\
\text { Empresa } \\
\end{array}$ & Escolaridade & Formação \\
\hline 1 & $\mathrm{~F}$ & Gerente & RH Corp. & 36 a 42 anos & 7 anos & $3^{\circ} \mathrm{Grau}$ & Psicologia \\
\hline 2 & M & Gerente & UPP Sólidos & 36 a 42 anos & 12 anos & $3^{\circ} \mathrm{Grau}$ & $\begin{array}{l}\text { Psicologia e } \\
\text { Engenharia }\end{array}$ \\
\hline 3 & $\mathrm{M}$ & Gerente & UPP Injetáveis & 36 a 42 anos & 8 anos & $3^{\circ} \mathrm{Grau}$ & Farmácia \\
\hline 4 & $\mathrm{M}$ & Gerente & UPP Líquidos & 43 a 49 anos & 23 anos & $3^{\circ} \mathrm{Grau}$ & Engenharia \\
\hline 5 & M & Farmacêutico & Tec. Industrial & 21 a 28 anos & 6 anos & $3^{\circ} \mathrm{Grau}$ & Farmácia \\
\hline 6 & M & Gerente & RH. Industrial & 36 a 42 anos & 3 anos & $3^{\circ} \mathrm{Grau}$ & $\begin{array}{c}\text { Administração de } \\
\text { Empresas }\end{array}$ \\
\hline
\end{tabular}

Fonte : Dados coletados das entrevistas

Os respondentes foram selecionados, com a orientação da área de $\mathrm{RH}$ da empresa. Os gerentes entrevistados operacionalizam e participam da formulação estratégica e estavam de acordo com a estruturação dos objetivos a serem alcançados pelo estudo.

\subsubsection{Coleta de dados}

Coletar dados é essencial para atingir o objetivo da pesquisa, portanto é necessário lançar mão de técnicas e instrumentos de coletas de dados. "O instrumento de coleta de dados é uma forma de comunicar a informação que é transmitida do respondente para o pesquisador" (RICHARDSON, 1999). 


\subsubsection{Entrevistas}

Richardson (1999) afirma que entrevista é uma técnica importante que permite o desenvolvimento de uma estreita relação entre as pessoas. É um modo de comunicação na qual determinada informação é transmitida do respondente para o pesquisador.

Neste artigo utilizou-se como instrumento de coleta de dados um roteiro de entrevista apresentado no Apêndice A e a técnica de entrevista propriamente dita, para sua aplicação.

O roteiro de entrevista utilizado teve como base os objetivos já mencionados neste estudo, buscando levantar informações sobre Estratégias de Negócio e competências individuais desenvolvidas pelos programas de Universidade Corporativa da empresa pesquisada.

\subsubsection{Ação para obtenção, registro e recuperação dos dados}

É necessário tomar uma série de cuidados a fim de que a coleta de dados seja eficaz e permita o tratamento adequado dos dados qualitativos. Como foi dito, os pesquisadores utilizaram um roteiro direcionado para a obtenção de informações sobre o(s) tipo(s) de estratégia(s) de negócio adotada(s) e sobre o desenvolvimento do capital humano dentro da empresa pesquisada.

Antes do início de cada entrevista foi explicado o objetivo e a natureza do trabalho, solicitou-se autorização para gravá-la e realizar anotações.

Procurou-se deixar uma "porta aberta" com os respondentes: em caso de se notar ausência de alguma informação importante haveria a possibilidade de questioná-la em um momento futuro, antes do término da pesquisa.

As entrevistas foram realizadas no parque fabril da empresa, nas salas dos entrevistados. Foi aplicada por uma dupla de pesquisadores, onde um entrevistador conduzia a entrevista, enquanto o outro anotava em um bloco de notas citações ou falas importantes. Este segundo também auxiliava o primeiro, levantando pontos com o entrevistado que não ficaram claros ou não foram citados.

Cada entrevista durou em média trinta minutos; nesse intervalo os entrevistados não se mostraram avessos nem fatigados. Os conteúdos foram transcritos (aproximadamente 20 horas), tomando-se o cuidado de manter as falas e assinalando-se as pausas e outras expressões dos respondentes.

\subsection{Tratamento dos dados}

Richardson (1999, p. 28), afirma que a Análise de Conteúdo é utilizada para estudar material de tipo qualitativo, "um conjunto de instrumentos metodológicos, cada dia mais aperfeiçoados, que se aplicam a discursos diversos". 
Segundo Bardin (2000), pode-se organizar as fases da análise de conteúdo por ordem cronológica:

- Pré-análise: É a fase de organização propriamente dita, visando operacionalizar e sistematizar as idéias, elaborando um esquema preciso de desenvolvimento do trabalho. Abrange três aspectos: a escolha do material, a formulação de hipóteses e objetivos e a elaboração dos indicadores para a interpretação dos resultados;

- Análise do material: Consiste basicamente na codificação, categorização e quantificação da informação;

- Tratamento dos resultados: a base da metodologia da análise de conteúdo está em como analisar ou tratar o material, interpretando-o depois de codificá-lo.

Dentre as atividades de cada uma das três etapas adotadas por Bardin, talvez a mais importante seja a codificação. Richardson (1999, p.34) afirma que "a codificação é uma transformação, seguindo regras especificadas dos dados de um texto, procurando agrupá-los em unidades que permitam uma representação do conteúdo desse texto", sugerindo ainda três passos fundamentais para que seja bem feita:

- Determinação das unidades de registro: definição das unidades de conteúdo que serão consideradas;

- $\quad$ Escolha das Regras de numeração: escolha do sistema de quantificação de dados que será utilizado, se for o caso;

- Definição das categorias de análise: definição do problema de pesquisa em termos de categoria.

Após a realização da análise dos elementos, segundo Richardson (1999), é necessário classificá-los, pois facilita a análise da informação. A análise por categoria é a mais antiga e a mais utilizada entre as diversas técnicas de análise de conteúdo. Bardin (2000) cita que os critérios de categorização podem ser:

- Semânticos: categoria temática;

- $\quad$ Sintáticos: verbos, adjetivos;

- $\quad$ Léxicos: classificação das palavras segundo seu sentido;

- $\quad$ Expressivo: categorias que classificam os problemas de linguagem.

Segundo Richardson (1999), a categorização pode ser realizada de duas maneiras: na primeira, o sistema de categorias é estabelecido de forma prévia e os elementos distribuídos da melhor forma possível entre as categorias a priori; na segunda, o sistema de categorias não é dado, resultando da classificação progressiva dos elementos a posteriori.

Neste estudo, as transcrições das seis entrevistas foram tratadas segundo análise de Conteúdo, utilizando-se como unidade de registro o tema e o critério semântico. As categorias 
foram definidas a priori, de acordo com o referencial teórico utilizado. Foram seguidas as etapas recomendadas por Bardin em 2000. Foram realizadas leituras flutuante das seis entrevistas, classificando seus conteúdos conforme categorias pré-definidas. Em seguida, reuniram-se para discutir os conteúdos de cada categoria, utilizando-se a análise de juízes (eles mesmos), quando não havia consenso na classificação. Foram também estabelecidas categorias a posteriori, na medida em que estas poderiam auxiliar na análise e interpretação dos dados.

\section{Apresentação, análise e interpretação dos resultados}

\subsection{Descrição da Farmacêutica S/A}

A empresa Farmacêutica S/A está hoje presente em 100 países, empregando cerca de 69 mil funcionários (dos quais cerca de 20.000 estão na força de vendas). A sede mundial está localizada na França. O centro global de desenvolvimento de medicamentos está localizado nos Estados Unidos. Existem também centros estratégicos de pesquisa em países europeus. A empresa conta com uma equipe global de aproximadamente 5.700 pesquisadores, além de parcerias estratégicas com inúmeras instituições acadêmicas e empresas de biotecnologia.

Com uma participação global de mercado de 3,5\%, está entre as dez maiores indústrias farmacêuticas do mundo, com forte presença nas áreas Cardiovascular, Antiinfectiva, Alergorespiratória, Diabetes e Oncologia.

$\mathrm{Na}$ empresa observam-se, globalmente, três grandes áreas com características distintas: Pesquisa \& Desenvolvimento, Operações Farmacêuticas (Comercial) e Assuntos Industriais (Produção).

\section{A Farmacêutica S/A no Brasil}

Concluída há cerca de quatro anos, a fábrica localizada próxima à cidade de São Paulo, é uma das mais modernas unidades farmacêuticas do grupo, cuja construção demandou investimentos da ordem de 100 milhões de dólares. Terceira indústria na América Latina a obter a aprovação ISO 14001, a unidade brasileira se junta a outras fábricas certificadas do Grupo, reafirmando o compromisso de desenvolvimento sustentável da organização.

Empregando mais de 630 funcionários diretos, o parque fabril produz cerca de 100 milhões de unidades anuais de medicamentos- divididas em mais de 380 apresentações diferentes, abastecendo tanto o mercado local quanto alguns países da América Latina.

Somente em 2005, a fábrica recebeu cerca de 4 milhões de dólares em investimentos na melhoria de seus processos produtivos e espera, este ano, ampliar suas exportações para o continente latino-americano. 
Foram realizadas, conforme mencionado nos procedimentos metodológicos, entrevistas com pelos executivos da área industrial da Farmacêutica S/A no Brasil: profissionais responsáveis pela Universidade Corporativa e Manufatura em cada uma das três Unidades de Produção, bem como um farmacêutico responsável pela área de Tecnologia Industrial (desenvolvimento de produto).

\subsection{Resultados da análise de conteúdo}

Os dados qualitativos obtidos a partir das seis entrevistas foram analisados empregando-se o método de Análise de Conteúdo por categorização a priori e a posteriori, conforme apresentado no Capítulo 3, visando alcançar os seguintes objetivos:

- Conhecer as estratégias de negócio da empresa,

- Conhecer as competências individuais que a Universidade Corporativa pretende desenvolver com seus programas de desenvolvimento organizacional.

\subsubsection{Objetivo 1: Conhecer as estratégias de negócio da empresa}

Para atingir este objetivo, foram analisados em primeiro lugar, os fatores que levam à formulação das estratégias da empresa, consideradas a partir tanto da perspectiva de "fora para dentro" (forças competitivas do setor) quanto de "dentro para fora" (recursos).

\subsubsection{Fatores que levam à elaboração de estratégias segundo a perspectiva de "fora para dentro"}

As entrevistas demonstraram uma atuação competitiva da Farmacêutica S/A no setor farmacêutico, de acordo com quatro categorias definidas a partir do modelo de Porter (1990): fornecedores, clientes, novos entrantes e concorrência. A energia ou o vigor de cada uma das forças está diretamente vinculado à estrutura de cada área de negócio (sólidos, líquidos e injetáveis) e são dependentes de uma série de avaliações, seja da política governamental, custos da mudança, diferenciação e identidade da marca, economia de escala, entre outras.

Em relação aos fornecedores nota-se relativa diversidade e especialização. Conseqüentemente, o número de fornecedores da Farmacêutica S/A é bastante elevado, no que tange ao mercado farmacêutico. Os fornecedores podem ser divididos basicamente em dois grupos: fornecedores de embalagens e de matéria-prima (princípio ativo). No caso dos fornecedores de embalagens, geralmente brasileiros, o poder de barganha é menor, pois existe grande diversidade. No caso das matérias primas, os fornecedores são provenientes da Índia e China, onde a mão-deobra é sensivelmente mais barata. 
No que diz respeito aos clientes da Farmacêutica S/A, entre os respondentes há divergências. A análise de conteúdo sobre os dados coletados nas entrevistas demonstra que podem ser considerados clientes: as áreas (clientes internos), distribuidoras, clientes diretos (pessoas comuns) e médicos. Para os clientes diretos, são veiculadas campanhas publicitárias, pois os produtos não necessitam de prescrição médica. Para os médicos, os produtos oferecidos são aqueles que, tendo que estar em conformidade com as normas legais, necessitam de prescrição médica. Nesse sentido, há procedimentos específicos para entrar em contato com este tipo de clientes.

Sobre o tópico novos entrantes, podemos observar dois pontos principais. O primeiro diz respeito à entrada de medicamentos genéricos no mercado, que constituiu um marco importante no mercado farmacêutico. Isso significou um aumento significativo no número de laboratórios no setor. O segundo diz respeito à necessidade de altos investimentos para a apresentação de novos produtos no mercado farmacêutico. Nesse sentido, para entrada de novos produtos, de forma competitiva, são necessários altos investimentos em P\&D, e estratégias específicas para a competição com medicamentos de concorrentes que já se firmaram no mercado.

Os resultados mostram a existência de uma acirrada concorrência no setor farmacêutico, além de um ambiente competitivo bastante dinâmico. A partir de 1999, observa-se uma grande mudança no contexto do mercado farmacêutico devido à reformulação da lei de patentes e à introdução dos produtos genéricos. Com isso, as empresas do setor tiveram que se adaptar, criando políticas específicas para lidar com esta nova realidade. O setor farmacêutico é caracterizado por um grande número de competidores e por um fracionamento bastante acentuado, onde o líder de mercado não possui mais de $7 \%$ de participação.

\subsubsection{Fatores que levam à elaboração de estratégias segundo a perspectiva de "dentro para fora"}

Conforme evidenciado no referencial teórico, o conceito de competência organizacional tem suas raízes na abordagem da organização como um portfólio de recursos, abrangendo os recursos físicos (infra-estrutura), financeiros, organizacionais (sistemas administrativos, cultura organizacional), recursos humanos e intangíveis (marca, imagem) (HAMEL; PRAHALAD, 1995). Esta tipologia proveu as categorias para análise de conteúdo no que diz respeito às estratégias na perspectiva de "dentro para fora", encontrando-se nas citações, quatro delas, a saber: recursos financeiros, organizacionais, físicos e humanos.

Sobre os recursos financeiros, nota-se uma necessidade de fortes investimentos, tanto para entrar no mercado como para manter-se vivo nele. Tratando-se do setor farmacêutico, encontra-se um grande número de exigências legais (burocracia) que o encarecem. Além disto, há outras razões para o produto custar muito, estes vem da concorrência e do próprio tipo de produto. Para competir, 
portanto, é necessário um enorme aporte de investimento.

Os recursos organizacionais são as estruturas, planejamento, controles, sistemas de coordenação, cultura, reputação, relações informais (HAMEL; PRAHALAD, 1995). Os respondentes consideram que a Farmacêutica S.A. possui capacidade informacional, provendo-lhe diferencial competitivo além de ser uma forma de reter talentos impactando na qualidade dos próprios recursos humanos.

Hamel e Prahalad (1995) definem os recursos físicos como tecnologias, fábricas, equipamentos, localização geográfica e acesso a matérias primas. Várias operações industriais na América Latina foram concentradas na filial brasileira visando maior ganho de escala. Ao analisar a categoria dos recursos físicos, notam-se duas fases no processo informacional. A primeira fase, referente ao descobrimento e desenvolvimento da molécula, demanda custos muito altos. Essa fase é, portanto, desenvolvida pela Farmacêutica S/A fora do Brasil. A segunda fase, relativa aos ensaios clínicos, caracteriza-se por processos eminentemente experimentais. Isto é, fórmulas elaboradas em outros países são testadas. Nessa fase, o Brasil apresenta grande vantagem, pela sua diversidade racial e boa cobertura da assistência médica.

A análise dos dados coletados em entrevista mostra que os recursos físicos têm conseqüências para o bom desempenho dos recursos humanos e organizacionais. Portanto, bons recursos físicos alavancam bons resultados humanos e organizacionais.

Os treinamentos, a experiência com a inteligência e a intuição dos executivos e funcionários são considerados recursos humanos (FLEURY; FLEURY, 2002). Várias operações industriais foram concentradas na filial brasileira visando maior ganho de escala. Com essa centralização, algumas competências humanas, as quais estão escassez no mercado se tornaram fatores críticos de sucesso.

\subsubsection{As estratégias de negócio da Farmacêutica S/A}

A abordagem dos recursos da firma enfatiza a maior importância de se centrar a formulação estratégica em um grupo específico de recursos - aqueles que garantem lucratividade de longo prazo (MILLS et al. apud FLEURY, 2002).

Tendo em vista o tema estratégias de negócio a serem seguidas para uma atuação competitiva no mercado farmacêutico, encontraram-se três categorias, consideradas a partir da classificação de Fleury e Fleury (2002): excelência operacional, orientação para clientes e produtos inovadores.

\section{Estratégia de Excelência Operacional}

As entrevistas mostraram que, de maneira geral, a Farmacêutica S/A compete com produtos padronizados ou normalizados. Uma das estratégias dela é a obtenção de excelência operacional 
onde a lucratividade decorre da margem por produto e da escala de produção (FLEURY; FLEURY, 2002).

\section{Estratégia de Produtos Inovadores}

As empresas que competem com uma estratégia de produtos inovadores estão continuamente investindo para criar conceitos de produtos radicalmente novos, para clientes e segmentos de mercado definidos. A função crítica é Pesquisa \& Desenvolvimento e Engenharia (P\&D\&E). Procuram oferecer aos seus clientes produtos de ponta, inovando sempre (FLEURY; FLEURY, 2002).

Nota-se, ao analisar os dados coletados das entrevistas, uma descentralização no processo de P\&D. Essa função é delegada às unidades internacionais da empresa que não a brasileira, responsáveis pela apresentação de novas fórmulas para serem produzidas no Brasil. Isso não significa que a $P \& D$ não assume importância chave para o andamento da empresa, para que mantenha suas vantagens competitivas.

\section{Estratégia de Orientação para clientes}

Nota-se que a Farmacêutica S.A. parece considerar esta estratégia uma vez que suas áreas são voltadas para as necessidades de clientes específicos, individualizados, procurando se especializar no desenvolvimento de produtos, sistemas e soluções que atendam às suas demandas atuais e futuras (FLEURY; FLEURY, 2002).

Nessa categoria, pode-se observar uma tendência, cada vez maior, de aproximar o produto do cliente. A empresa encara a apresentação do produto, direto aos clientes, como uma forma de prestação de serviços complementares, mas necessária. O setor de vendas da Farmacêutica S.A. objetiva, portanto, trabalhar para diminuir, o máximo possível, os empecilhos resultantes da distância e das dificuldades de acesso ao produto.

\subsubsection{Considerações sobre Objetivo 1}

Pelas entrevistas e pela análise de conteúdo efetuada, as três categorias propostas por Fleury e Fleury (2002) foram encontradas.

Fazendo um paralelo com as estratégias de Porter (1999), a estratégia de excelência operacional, proposta por Fleury e Fleury (2002), pode ser relacionada à estratégia genérica de liderança de custo, onde o foco da empresa está voltado para produzir com baixo custo dentro de seu setor, visando obter o menor custo em relação à concorrência.

Já as estratégias de produtos inovadores e orientação para clientes (FLEURY; FLEURY, 2002) parecem estar relacionadas à estratégia de enfoque proposta por Porter (1999). Para isso, a empresa deve desenvolver atividades com alta qualidade, de tal forma a gerar oferta de benefícios diferenciados que torne o seu produto mais atraente aos olhos do consumidor do que o de seus 
concorrentes (PORTER, 1999).

Assim a Farmacêutica S/A, em função dos resultados obtidos, parece adotar uma mescla de todas as estratégias, fazendo relação com os fatores (elementos externos e internos à organização), esta relação é obtida através da adoção de um conjunto de políticas funcionais voltadas para este objetivo, bem como o desenvolvimento de atividades econômicas e tecnológicas a um custo menor que a de seu concorrente sem perder a qualidade do produto final.

\subsubsection{Objetivo 2: Conhecer as competências individuais que a Universidade Corporativa pretende desenvolver com seus programas de desenvolvimento organizacional}

Antes de serem contempladas as análises referentes às competências individuais, serão apresentadas algumas categorias a posteriori, extraídas das entrevistas que permitem entender melhor o sistema de gestão dos recursos humanos da Farmacêutica S/A e as características das iniciativas de aprendizado de sua Universidade Corporativa.

\subsubsection{A gestão de recursos humanos na Farmacêutica S/A}

Pelas entrevistas, foram citadas duas concepções na gestão de Recursos Humanos, a "formadora" de recursos e "consumidora" de recursos. A formadora de recursos "vende projetos consistentes", numa abordagem integrada. A "consumidora" de recursos vende "sonhos": salário, qualidade de vida, focada muito mais na remuneração, como elucidam algumas citações:

A Farmacêutica S/A parece dar ênfase à formação dos recursos humanos, pelo fato de se localizar fora da "área de conveniência" das pessoas, age formando recursos humanos e capacitando seus profissionais.

Outro aspecto importante, segundo o Gerente da UPP Injetáveis, é a não-sazonalidade do setor farmacêutico, destacando-se a visão de longo prazo da Farmacêutica S/A.

O Gerente de RH da Industrial resume a gestão estratégica de recursos humanos da Farmacêutica S.A, dando ênfase à estratégia "formadora", na medida em que se dá prioridade ao recrutamento interno.

\subsubsection{As iniciativas de aprendizado da Farmacêutica S/A}

As universidades corporativas, como qualquer instituição que promove ensino e aprendizagem, têm em sua estrutura programas, métodos, técnicas e parceiros que, interagindo, buscam atender a objetivos pré-estabelecidos. De maneira geral, os programas são constituídos por módulos afins, que buscam desenvolver um conjunto de competências para a organização como um todo (MARCONDES; PAIVA, 2001).

A seguir, são apresentadas as iniciativas de aprendizado da Universidade Corporativa da 
Farmacêutica S/A e como eles se posicionam para a formação das competências necessárias ao negócio. As iniciativas de aprendizado da Farmacêutica S/A são traduzidas em programas de desenvolvimento (isto é, para cada iniciativa dessas corresponde uma série de ações).

\section{Abordagem de Projetos}

Nas entrevistas, notou-se uma característica em comum em todas as áreas da empresa: a visão baseada em projeto. Esta é fundamentalmente usada para atrair novos profissionais, como também para treinar os funcionários, tornando-os multifuncionais.

\section{Desenvolvimento Comportamental}

Uma outra característica das iniciativas de aprendizado da Farmacêutica S/A diz respeito ao desenvolvimento comportamental. O aprendizado não só é visto no desenvolvimento profissional como também nas características que podem influenciar no processo, como fatores motivacionais.

\section{Programa de Estágio}

Diante da adversidade de se recrutar no ambiente da Grande São Paulo e de não competir de igual para igual com os demais concorrentes, fez-se necessário criar um programa de estágio bemestruturado no qual as competências são desenvolvidas. Este supre a saída eventual de funcionários.

\section{Treinamento Técnico/Capacitação}

Conforme Éboli (2002) a Universidades Corporativas têm por finalidade a educação e o desenvolvimento da cadeia de valor (empregados, fornecedores, clientes, acionistas, franqueador) com o objetivo de atender às estratégias empresariais de uma organização. Nas entrevistas, percebese a preocupação em capacitar outros públicos de interesse que não os empregados, desde os fornecedores até o médico, consumidor final.

Dentre as iniciativas de treinamento, estão os treinamentos para a base da estrutura organizacional da Farmacêutica S/A.

\section{Programa Educacional}

Foi possível notar pela análise das entrevistas que a universidade corporativa da Farmacêutica S/A considera como um de seus pilares o programa educacional. Nele são oferecidos cursos de graduação, pós-graduação e MBA tanto para operadores quanto para lideranças intermediárias e gerências.

\section{Treinamento On-the-Job}

O treinamento no trabalho foi uma característica nas entrevistas coletadas, os funcionários têm um aprendizado no próprio local de trabalho.

Dentro desta iniciativa de aprendizado, notou-se a atuação dos próprios empregados da Farmacêutica S/A como facilitadores de aprendizagem como sugere Goulart e Pessoa (2004), alocado em cada unidade da empresa, formando uma rede de distribuição presencial e virtual de conhecimento. 


\section{Considerações sobre as iniciativas de aprendizado}

Os programas da universidade corporativa da Farmacêutica S/A mostraram-se como um dos focos da empresa. Os mesmos procuram atuar tanto na parte comportamental até a parte técnica. Observam-se muitas competências, tais como: um bom trabalho em equipe, pessoas multifuncionais, inovação, transferência de produtos, constituição de recursos e validação dos processos.

\subsubsection{As competências individuais desenvolvidas mediante programas da Universidade Corporativa da Farmacêutica S/A}

Utilizou-se de categorias a priori para a análise das competências individuais desenvolvidas pela universidade corporativa da Farmacêutica S/A, tomando-se como base a classificação de Fleury e Fleury (2002), apresentada no referencial teórico.

Foram encontradas as três categorias: competências de negócio, técnico-profissionais e sociais, a partir dos relatos dos respondentes.

\section{Competências de negócio}

A primeira categoria são as competências relacionadas à compreensão do negócio, seus objetivos em relação ao mercado, clientes e competidores, assim como no ambiente político e social (FLEURY; FLEURY, 2002).

Os gerentes declaram a existência de uma visão estratégica do negócio, mesmo nos níveis operacionais. A Farmacêutica S/A treina para que as pessoas se insiram no negócio da empresa.

Para a Farmacêutica S/A mostram-se importantes as características ligadas à inovação, e à identificação da necessidade de mudanças e, conseqüentemente, competências necessárias para identificar os desafios do negócio, da mesma forma que sugeriu Fleury e Fleury (2002). Este mesmo desafio foi encontrado no estudo de Marcondes e Paiva (2001).

Observa-se também o planejamento como competência. É importante estabelecer mecanismos de controle de validação das ações, elaborado pela área de Qualidade e Compliance da Farmacêutica S/A, para sanar as falhas e otimizar os recursos existentes.

\section{Competências técnico-profissionais}

O segundo bloco refere-se a competências específicas para certa operação, ocupação ou atividade, tais como o conhecimento do produto e de finanças (FLEURY; FLEURY, 2002).

Nesse sentido, as entrevistas demonstraram algumas competências individuais, como o desenvolvimento de projetos e produtos. Observou-se a utilização e atualização de conhecimentos técnicos relativos a cada área.

As competências técnicas relacionadas ao nível operacional. foram: Qualidade, Higiene e Segurança, Procedimentos, 6 Sigma e Kaizen. 
No discurso do Gerente de RH da Industrial podem ser encontradas parcerias com instituições de ensino. Os programas são estabelecidos para desenvolver esta liderança intermediária.

\section{Competências sociais}

A terceira categoria são as competências sociais. Elas são necessárias para interagir com as pessoas. Estas competências estão relacionadas à comunicação, negociação, mobilização para mudança, sensibilidade cultural, trabalho em times (FLEURY; FLEURY, 2002).

As competências sociais que se pode depreender das falas foram interdisciplinaridade, trabalho em equipe, habilidade de negociação e de comunicação.

O Gerente da UPP Sólidos deixa claro as iniciativas de aprendizado focadas na habilidade de liderança para os supervisores.

\subsubsection{As relações entre estratégias de negócios e competências individuais}

Segundo Fleury e Fleury (2002) existem três tipos de estratégia, que representam modelos simplificados da realidade empresarial, e outros três tipos de competências individuais. Tendo por base as entrevistas feitas, assim como a análise de conteúdo efetuada, as três categorias, tanto as relativas a estratégias quanto a competências individuais propostas, foram encontradas na empresa estudada.

A estratégia de excelência operacional requer da empresa maior ênfase no desenvolvimento de competências na área de operações (FLEURY; FLEURY, 2002). Isto vem ao encontro dos resultados obtidos para a empresa que parece adotar tal estratégia, desenvolvendo para isso competências técnico-profissionais tais como conhecimento do produto. Ao fazer parte do jogo competitivo do setor farmacêutico, a Farmacêutica S/A otimiza a relação qualidade/preço, obtendo parte da sua lucratividade diretamente da margem do produto e da escala de produção.

Já a estratégia de produtos inovadores foca seus esforços para as competências em pesquisa, desenvolvimento e engenharia. As competências de negócio observadas na análise de conteúdo das entrevistas indicaram a necessidade de mudanças e as competências necessárias para enfrentar os desafios do negócio (FLEURY; FLEURY, 2002). Portanto, pode-se pensar que a Farmacêutica S/A, à medida que busca o desenvolvimento de tais competências, está dando condições a seus empregados de contribuírem com suas ações para a realização da estratégia de produtos inovadores, também identificada. Empresas que utilizam tal estratégia estão continuamente investindo para criar conceitos de produtos radicalmente novos, para clientes e segmentos de mercados definidos, como no caso da organização objeto de estudo.

Para Fleury e Fleury (2002) a estratégia de orientação para clientes, leva às empresas que as adotam a focarem nas competências Vendas \& Marketing. As competências sociais apresentadas 
nas entrevistas buscam promover o relacionamento interpessoal, trabalho em equipe e liderança. Deste modo pode-se pensar que a empresa estudada, ao adotar esta estratégia também busca desenvolver nos empregados tais competências, o que lhes permite especializarem-se em satisfazer, e até antecipar, os desejos do cliente em virtude de sua proximidade com os médicos.

Apesar dos três tipos de competências serem necessárias para qualquer organização que pretenda continuar fazendo parte do jogo do mercado, pode-se pensar que dependendo do tipo de estratégia predominante, determinados conjuntos de competências podem ser mais enfatizados (FLEURY; FLEURY, 2002).

Desta maneira foram identificadas as três estratégias e as três categorias de competências, pode-se pensar que o desenvolvimento de pessoas tenha relação com as estratégias uma vez que estas, para se concretizarem, precisam de pessoas com competências que lhes permitam otimizar processos, inovar e anteciparem-se às necessidades dos clientes.

\section{Conclusão, limites da pesquisa e recomendações de novos estudos}

\subsection{Conclusão}

O objetivo geral da pesquisa foi descobrir se existem relações entre estratégias de negócios e as competências individuais desenvolvidas pelos programas da Universidade Corporativa.

A partir dos resultados da pesquisa, foi identificado que a formulação estratégica na empresa ocorre de forma estruturada, levando em consideração diversos fatores, tanto em uma abordagem "de fora para dentro" quanto "de dentro para fora". A análise de conteúdo demonstrou que a Farmacêutica S/A parece considerar na formulação de suas estratégias fatores "de fora para dentro", estando presentes quatro das cinco forças competitivas conceituadas por Porter: fornecedores, clientes, novos entrantes e concorrentes. Quanto aos elementos considerados na formulação de estratégias segundo uma perspectiva "de dentro para fora” identificou-se a relevância dos recursos físicos e humanos.

Observou-se também que através da prática de treinamento, a empresa procura minimizar o risco de ações inesperadas, por influência das forças competitivas, desenvolvendo seus recursos humanos e otimizando os recursos físicos disponíveis.

Deste modo, para que a Farmacêutica S/A alcance um espaço competitivo num ambiente empresarial de turbulências é necessária a interdependência de seus recursos, numa visão integrada de gestão, onde recursos tangíveis possam dialogar de forma eficaz e equilibrada.

Não foi uma preocupação da pesquisa verificar os resultados das ações de iniciativas de aprendizado, por meio, por exemplo, de indicadores nem tampouco o conteúdo dos cursos.

No entanto, observa-se a presença do desenvolvimento de três tipos de competências 
individuais na Farmacêutica S/A relacionadas com as estratégias da empresa:

- $\quad$ competências de negócio: são aplicadas aos empregados de nível intermediário,

- competências técnico-profissionais: desenvolvidas na grande maioria dos empregados,

- $\quad$ competências sociais: aplicadas aos empregados de nível de liderança, que possuam subordinados.

Percebeu-se pela análise das entrevistas que a empresa estudada parece dar ênfase ao desenvolvimento de Competências Técnico-Profissionais, onde existem treinamentos de: Qualidade, Higiene e Segurança, Procedimentos, 6 Sigma e Kaizen estes aplicados em sua maioria, a empregados de nível operacional, visando atingir a excelência operacional, uma estratégia que busca otimizar a relação qualidade/preço. Com este resultado, pode-se pensar que há indícios de que a empresa objeto de estudo priorize essa estratégia em detrimento das demais.

Outra possibilidade é pensar que caso esta estratégia não seja a predominante, pode ser que haja um descompasso entre as competências individuais que a universidade corporativa da Farmacêutica S/A mais se preocupa em desenvolver e a estratégia da organização.

Como questionamentos que foram surgindo a partir da análise dos dados tem-se: será que as demais empresas do setor farmacêutico adotam estratégias semelhantes às da empresa estudada e enfatizam determinado grupo de competências individuais? Será que não são essas escolhas da Farmacêutica S/A (ou seja, escolhas em relação às estratégias e ao desenvolvimento de competências) que fazem dela a líder de mercado?

\subsection{Limites e sugestões de pesquisas}

A primeira limitação do estudo é a impossibilidade de generalização dos resultados, por ter sido feito em uma única empresa.

Também aos pesquisadores só foi possível realizar entrevistas, em sua maioria, com membros da área industrial da Farmacêutica S/A Esta escolha dos executivos da fábrica (e não da empresa como um todo) foi em função do acesso dos pesquisadores a essa divisão, o que pode ter causado um viés, principalmente em relação ao levantamento das estratégias da organização. Portanto, pode-se pensar em ampliar o estudo, abrangendo executivos que representem todas as áreas da organização, ou então, os níveis de diretoria.

Uma terceira limitação é que foram identificadas as competências individuais, mas não quanto elas são resultado da ação dos programas da Universidade Corporativa, esta indagação é um ponto de interrogação, algo a ser verificado com novas pesquisas. 


\title{
5.3 Sugestões para novas pesquisas
}

Como recomendações futuras, sugerem-se estudos que elucidem a influência dos estudos sobre a organização por times de projetos e pesquisas que possibilitem o real ganho de competência obtido através dos programas da Universidade Corporativa.

\begin{abstract}
This study aims to discuss the relations among business-oriented strategies and the abilities Corporative University programs may consider to develop their employees. Business strategies have been studied in two perspectives: strategies based on the analysis of the products, consumers and competitors and strategies based on the combination of abilities of development and resource's improvement. Concerning the Corporative University there were analyzed its learning decisions and its outputs in relation to individual abilities development. A study of exploratory nature was carried and the qualitative method was used, with research based on interviews in a large private company of the pharmaceutical sector. Later on, analysis of content for a specific categorization was used as a technique of data handling. The results had evidenced that the organization considers both internal and external factors in the formularization of its strategies, and that the Corporative University contributes by means of its programs to the development of abilities that help the collaborators to make the strategies be transformed into actions and results.
\end{abstract}

Key-words: business strategies, Corporative University, Pharmaceutical industry.

\section{Referências}

BARDIN, L. Análise de conteúdo. Portugal: Edições 70, 2000

BECHARA, F. CIRILO, R. Educação corporativa- fundamentos e práticas, São Paulo, 2004.

CERVO, A.; BERVIAN, P. Metodologia científica. São Paulo: Pearson Education do Brasil, 2002.

DENGO, N. Universidades Corporativas: Modismo ou Inovação? Programa de Pós-Graduação em Administração/Escola de Administração/Universidade Federal do Rio Grande do Sul - PPGA/EA/UFRGS, 2002.

ÉBOLI, M. Educação corporativa no Brasil: mitos e verdades - São Paulo: Editora Gente, 2002

ÉBOLI, M. Desenvolvimento e alinhamento dos talentos humanos às estratégias empresariais: o surgimento das universidades corporativas. São Paulo: Schmukler editores Ltda., 1999.

ÉBOLI, M. Universidade corporativa: ameaça ou oportunidade para as escolas tradicionais de administração. Revista de administração/Faculdade de Economia, Administração e Contabilidade da Universidade de São Paulo. São Paulo: FEA/USP out./dez. 1999.

ÉBOLI, M. “Gestão do conhecimento como vantagem competitiva: o surgimento das universidades corporativas: educação para as empresas do século XXI”. São Paulo: Schmukler, 1999

FISCHER, A. L. et al. As pessoas na organização, $3^{a}$ Edição, São Paulo: Gente, 2002.

FLEURY, M. T. L; FLEURY, A. Estratégias empresariais e formação de competências: Um quebra-cabeça caleidoscópio da indústria brasileira. $3^{\text {a }}$ edição. São Paulo: Atlas, 2002.

GDIKIAN, E.; SILVA, M. Educação estratégica nas organizações. Rio de Janeiro: Qualitymark, 2002.

GIL, A. C. Como elaborar projetos de pesquisa. 3. ed. São Paulo: Atlas, 1996.

GODOY, A.; ALVES, M. V Seminário de metodologia - método qualitativo - $1^{\circ}$ Semestre, 2004.

GOULART, S.; PESSOA, E. Educação corporativa como base da estratégia organizacional. Editora Quality Mark.- Rio de Janeiro,2004. 
HAMEL, G., PRAHALAD, C. K., Competindo pelo futuro: estratégias inovadoras para obter o controle do seu setor e criar os mercados de amanhã. (trad. Outras Palavras) Rio de Janeiro: Campus, 1995.

HITT, M., IRELAND, D.; HOSKISSON, R. Administração estratégica, Editora Thomson, São Paulo, 1990.

MARCONI, M A; LAKATOS, E. M. Técnicas de pesquisa. 5ªed. São Paulo: Atlas, 2002.

MARCONDES, R. C. M.; PAIVA, J. de P. Afinal, a universidade corporativa é uma T\&D revisitada? São Paulo, 2001.

MEISTER, J. Educação corporativa. São Paulo: Makron Books, 1999.

PORTER, M. Estratégia Competitiva: técnicas para análise da indústria e da concorrência. Ed. Campus, 1980. Estratégia competitiva - técnicas para análise de indústrias e da concorrência. São Paulo, Campus, 1986. Vantagem competitiva: criando e sustentando um desempenho superior. Rio de Janeiro, Campus, 1990. Competição $=$ On competition: estratégias competitivas essenciais. Rio de Janeiro, Campus, 1999.

RICHARDSON, R. Pesquisa social: métodos e técnicas. São Paulo: Atlas, 1999.

TREACY, M.; WIERSEMA, F. A disciplina dos líderes de mercado: escolha seus clientes, direcione seu foco, domine seu mercado. Rio de Janeiro: Rocco, 1995

Nome completo: João Victor Bonini Viana

Escola Politécnica da Universidade de São Paulo

Departamento: Engenharia de Produção

Endereço: Rua Nelson Antonio 19, Apt ${ }^{\circ} 09$ São Paulo - SP, CEP 05417-060

Telefones para contato: (11) 8114-5149

e-mail:jvbv@terra.com.br

Nome completo: Dr. Roberto Marx

Escola Politécnica da Universidade de São Paulo

Departamento: Departamento de Produção

Função ou cargo ocupado: Professor

Endereço: Av. Prof. Almeida Prado, Travessa 2 núm. 128, Cid. Universitária, São Paulo, SP, Brasil, CEP 05508-900.

Telefones para contato: (11) 3091-5363 Ramal:478

e-mail:robemarx@usp.br

Enviado em: 08/02/2010

Aprovado em: 03/03/2011 